\title{
Surgical Treatment of Femoroacetabular Impingement
}

\section{A Systematic Review of the Literature}

\author{
John C. Clohisy MD, Lauren C. St John BS, \\ Amanda L. Schutz PhD
}

Published online: 15 October 2009

(C) The Association of Bone and Joint Surgeons (B) 2009

\begin{abstract}
The surgical treatment of femoroacetabular impingement has become more common, yet the strength of clinical evidence to support this surgery is debated. We performed a systematic review of the literature to (1) define the level of evidence regarding hip impingement surgery; (2) determine whether the surgery relieves pain and improves function; (3) identify the complications; and (4) identify modifiable causes of failure (conversion to total hip arthroplasty). We searched the literature between 1950 and 2009 for all studies reporting on surgical treatment of femoroacetabular impingement. Studies with clinical outcome data and minimum two year followup were analyzed. Eleven studies met our criteria for inclusion. Nine were Level IV and two were Level III. Mean followup was 3.2 years; range (2-5.2 years). Reduced pain and improvement in hip function were reported in all studies. Conversion to THA was reported in $0 \%$ to $26 \%$ of cases. Major complications occurred in $0 \%$ to $18 \%$ of the procedures. Current evidence regarding femoroacetabular impingement surgery is primarily Level IV and suggests the various surgical techniques are associated with pain relief and improved function in $68-96 \%$ of patients over
\end{abstract}

One or more of the authors (JCC) has received funding from the National Center For Research Resources (Award Number UL1RR024992). The content is solely the responsibility of the authors and does not necessarily represent the official views of the National Center for Research Resources or the National Institutes of Health. This work was also supported in part by the Curing Hip Disease Fund (JCC) and a Hip Society Grant awarded by the Orthopaedic Research and Education Foundation (JCC).

J. C. Clohisy ( $₫)$, L. C. St John, A. L. Schutz

Department of Orthopaedic Surgery, Washington University

School of Medicine, One Barnes-Jewish Hospital Plaza,

Suite 11300 West Pavilion, St Louis, MO 63110, USA

e-mail: jclohisy@wustl.edu; clohisyj@wudosis.wustl.edu short-term followup. Long-term followup is needed to determine survivorship and impact on osteoarthritis progression and natural history.

Level of Evidence: Level IV, therapeutic study. See Guidelines for Authors for a complete description of levels of evidence.

\section{Introduction}

Over the past decade, the concept of femoroacetabular impingement (FAI) has been refined [26] and this constellation of disorders has been accepted as a common source of hip pain and dysfunction in young, active patients [11]. There is substantial evidence supporting the hypothesis that FAI is a major etiologic factor in the pathophysiology of secondary osteoarthritis of the hip [1, 5, $6,13,17,18,25,27,38-40]$. Specifically, FAI is associated with a pathomechanical hip environment in which there is abnormal, repetitive abutment between the anterolateral femoral head-neck junction and the anterolateral rim of the acetabulum [17, 36]. These abnormal joint mechanics stem from a heterogeneous group of structural abnormalities in which there is a femoral-based (cam), acetabular-based (pincer), or combined impingement deformity [28, 34, 36, 37]. These deformities initiate a cascade of degenerative, intraarticular events including disruption of the labrochondral junction. Chondromalacia and delamination of the peripheral acetabular rim cartilage with adjacent acetabular labral disease are common characteristics in acetabular rim disease $[17,38]$. As these focal lesions of the acetabular rim complex progress over time, more extensive, nonfocal degenerative disease ensues [5, 14].

In light of this contemporary understanding of FAI, a variety of surgical techniques have been utilized to treat 
prearthritic and early arthritic hip impingement disease [10]. These techniques include surgical dislocation of the hip [4, 6, 14, 16, 29, 30], periacetabular osteotomy [35], combined hip arthroscopy and a limited open exposure [12, 20, 24], and all other arthroscopic techniques [2, 8, 9, 19, 21-23, 31-33]. The goals of these surgical interventions are to relieve pain, enhance activity and function, and preserve the natural hip over time [3]. Although these surgical techniques stem from sound rationale regarding hip impingement disease, the published clinical results associated with these procedures are limited [7]. Therefore, there exists a major need to evaluate the current clinical evidence regarding hip impingement surgery.

We therefore performed a systematic review of the literature regarding the surgical treatment of FAI to (1) determine the level of clinical evidence regarding FAI surgery; (2) determine whether impingement surgery relieves pain and improves hip function; (3) identify complications associated with these procedures; and (4) identify modifiable causes of failure.

\section{Materials and Methods}

We searched PubMed, EMBASE, Cumulative Index to Nursing and Allied Health (CINAHL), and the Cochrane Library on December 12, 2008, for articles published between 1950 and 2009. A second search was performed on May 1, 2009, to identify additional articles. The search terms used were "femoroacetabular," "femoroacetabular impingement," "femoral head neck osteoplasty," "femoral osteochondroplasty," "femoral osteoplasty," "hip impingement," "surgical dislocation impingement," "treatment hip impingement," and "trochanteric flip osteotomy." Additionally, a hand search of the following journals was performed to screen for articles published between December 2008 and April 2009: Clinical Orthopaedics and Related Research, The Journal of Bone and Joint Surgery (British and American editions), Acta Orthopaedica, Journal of Arthroplasty, and International Orthopaedics. Bibliographies of the included studies were also searched to identify relevant studies. All citations were imported into EndNote ${ }^{\circledR}$ to remove duplicate studies. Collectively, our searches identified 2834 articles. Each article underwent abstract review by one of the authors (LSJ) (Fig. 1). Full-text publications were obtained for studies that appeared to be relevant and potentially meet our inclusion criteria. Two reviewers (LSJ, ALS), after reviewing each full report, independently assessed eligibility of all relevant studies based on our inclusion criteria. Disagreements between the reviewers were resolved by discussion. Studies were included only if they were peer-reviewed, published in English, reported clinical outcome of hip impingement surgery, had a minimum of 2 years followup, and were not descriptions of previously reported findings. All study designs from Level I to IV were eligible. Of the 2834 articles, 20 met our inclusion criteria. Eight articles were excluded because they were case reports or reviews. One additional article was excluded because it focused on indirect deformity correction with proximal femoral osteotomies. Therefore, 11 studies met our eligibility criteria and underwent comprehensive quality appraisal and review (Table 1).
Fig. 1 A flow diagram shows the method of article selection for study inclusion.

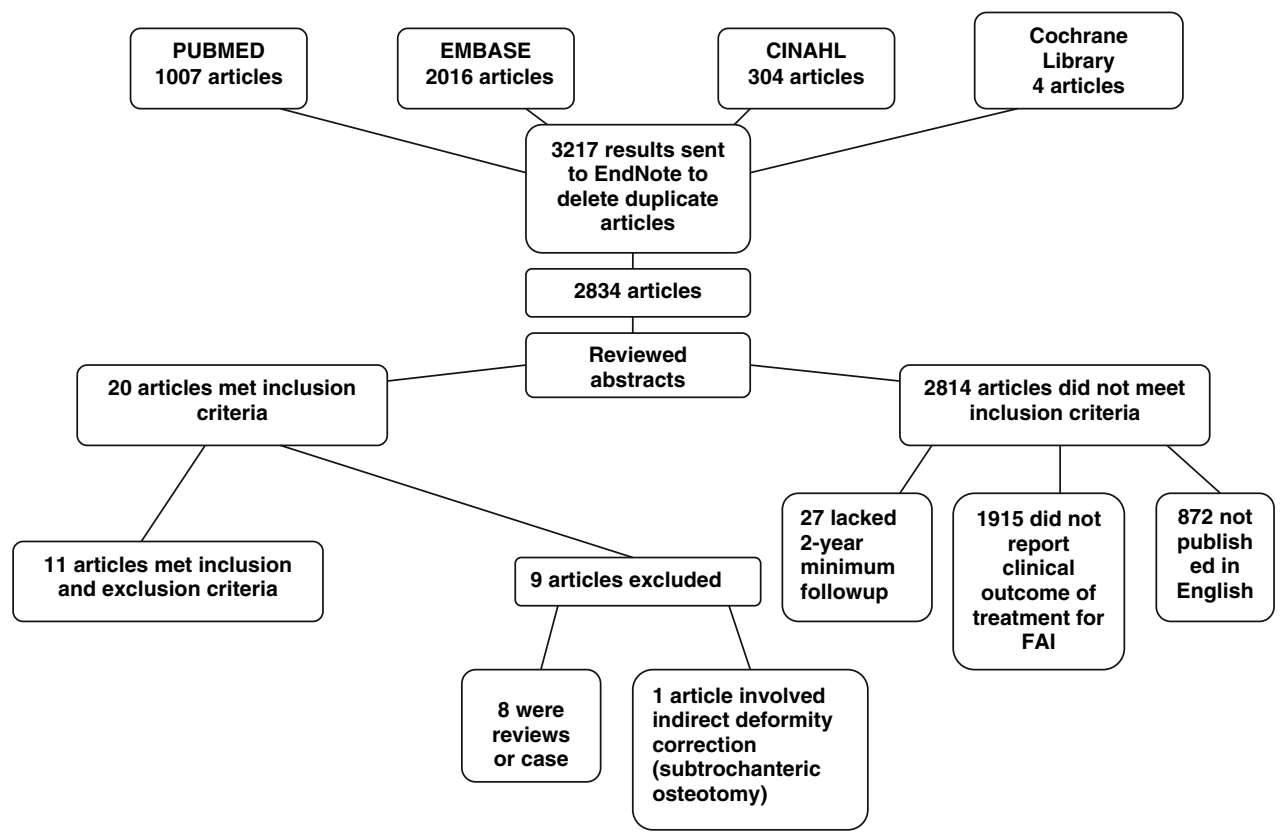




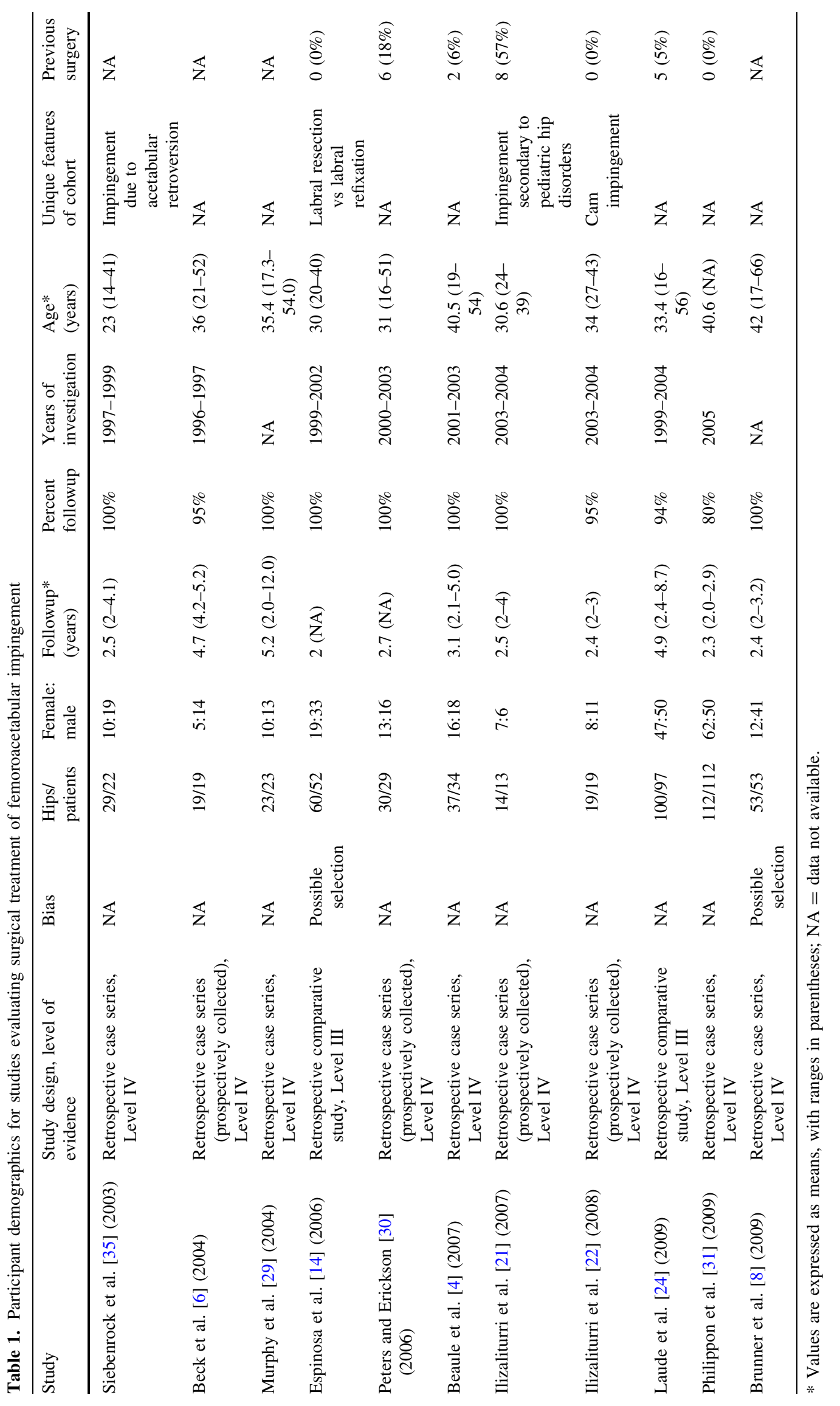




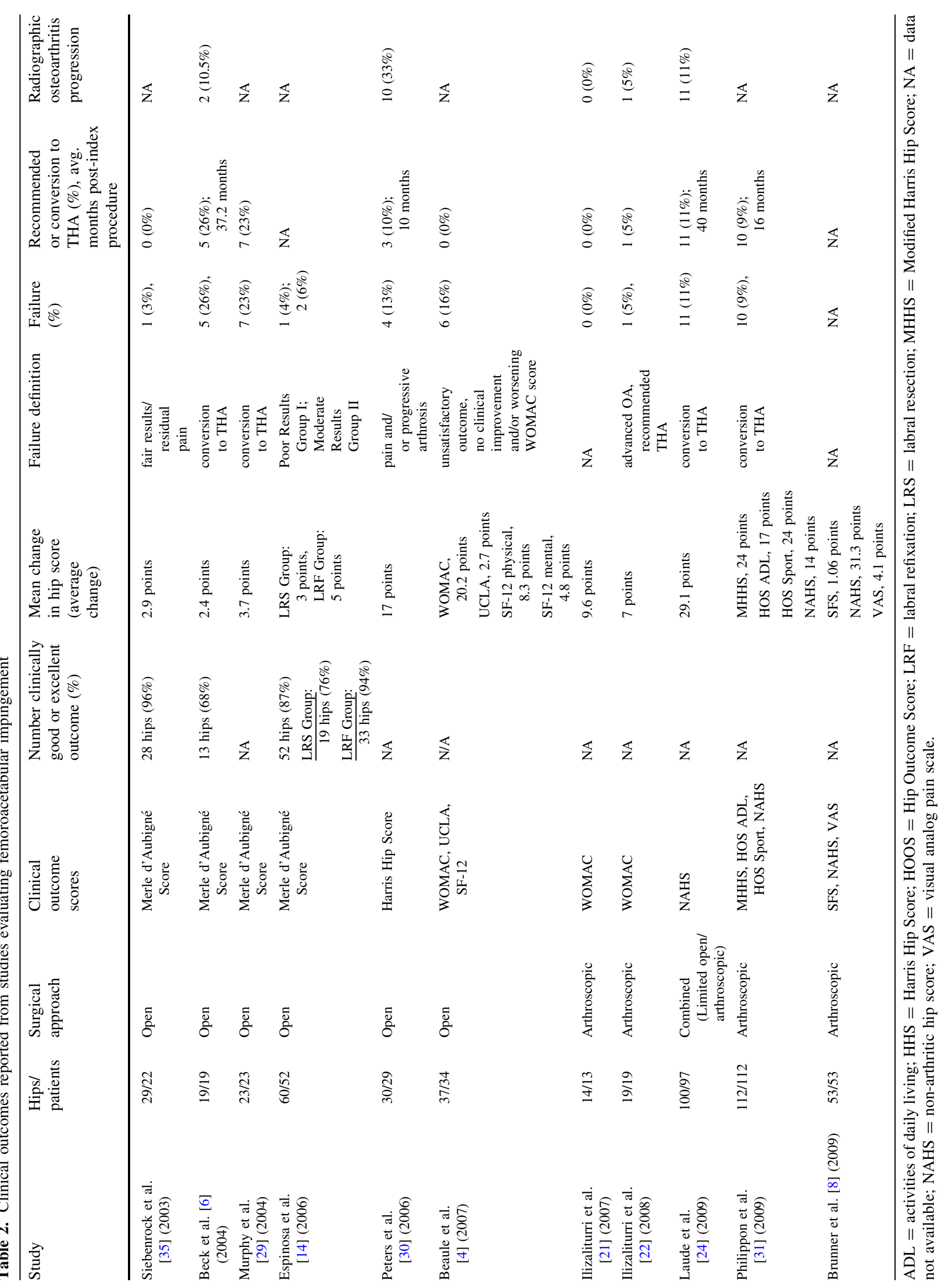




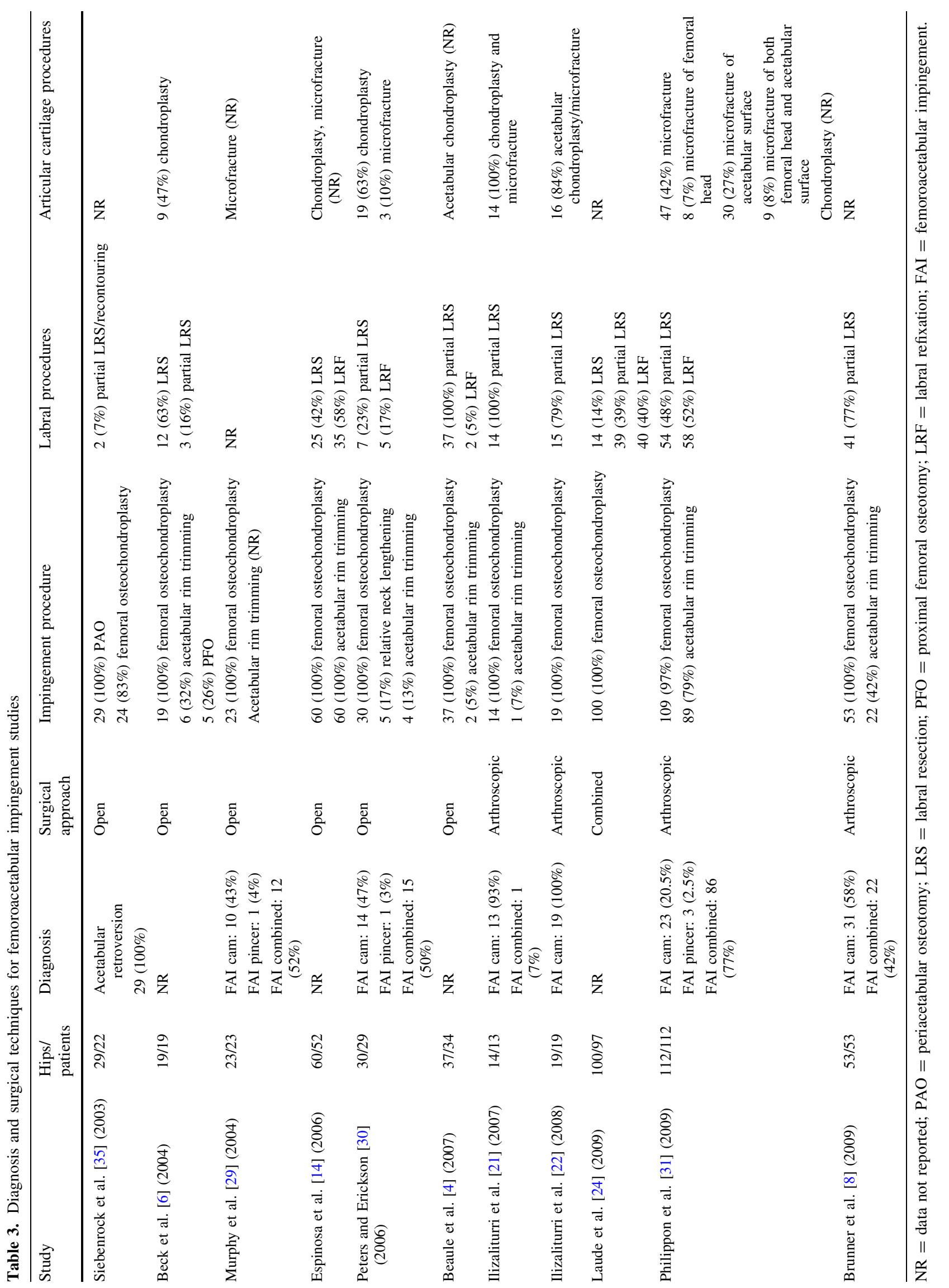




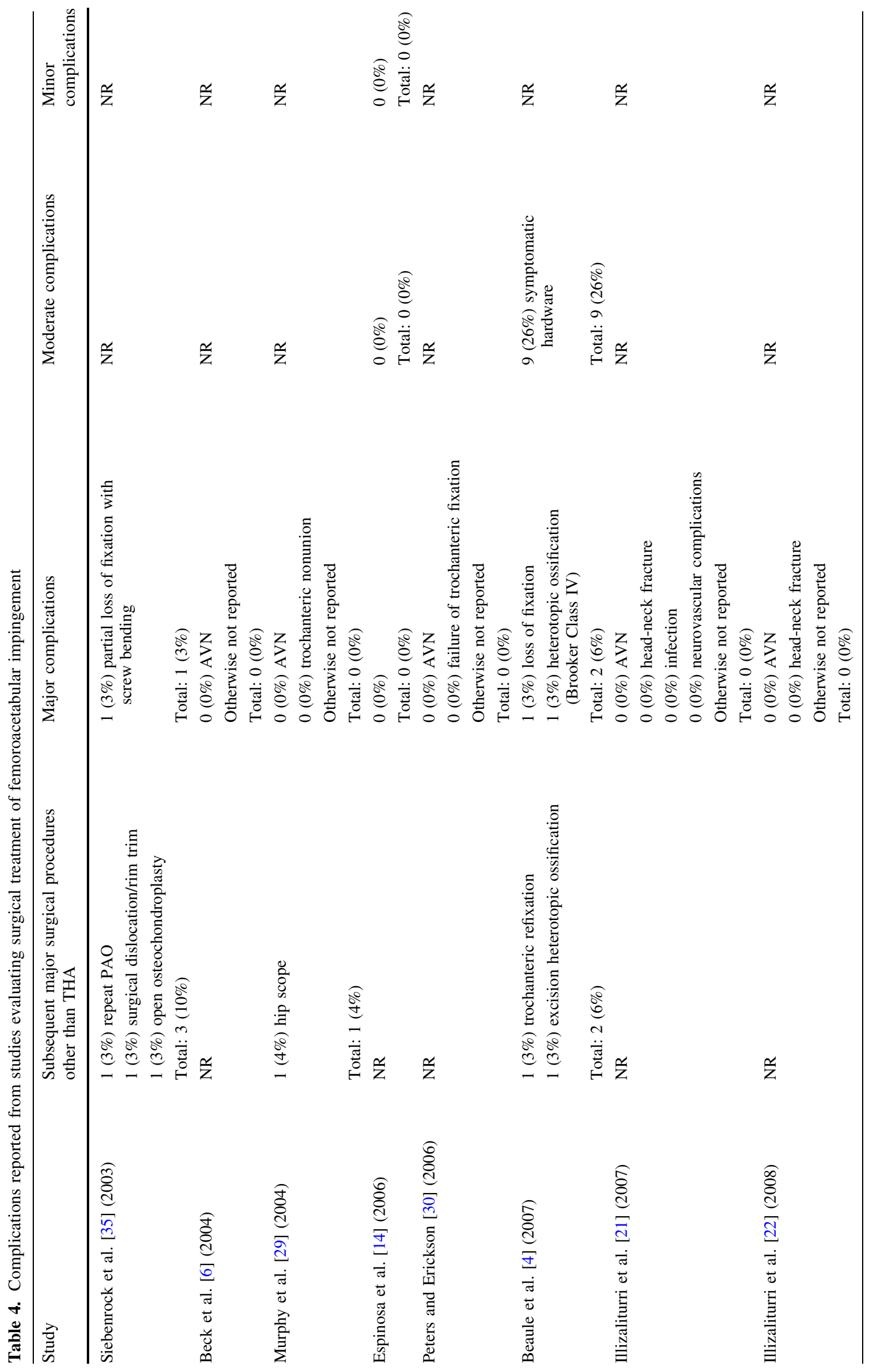




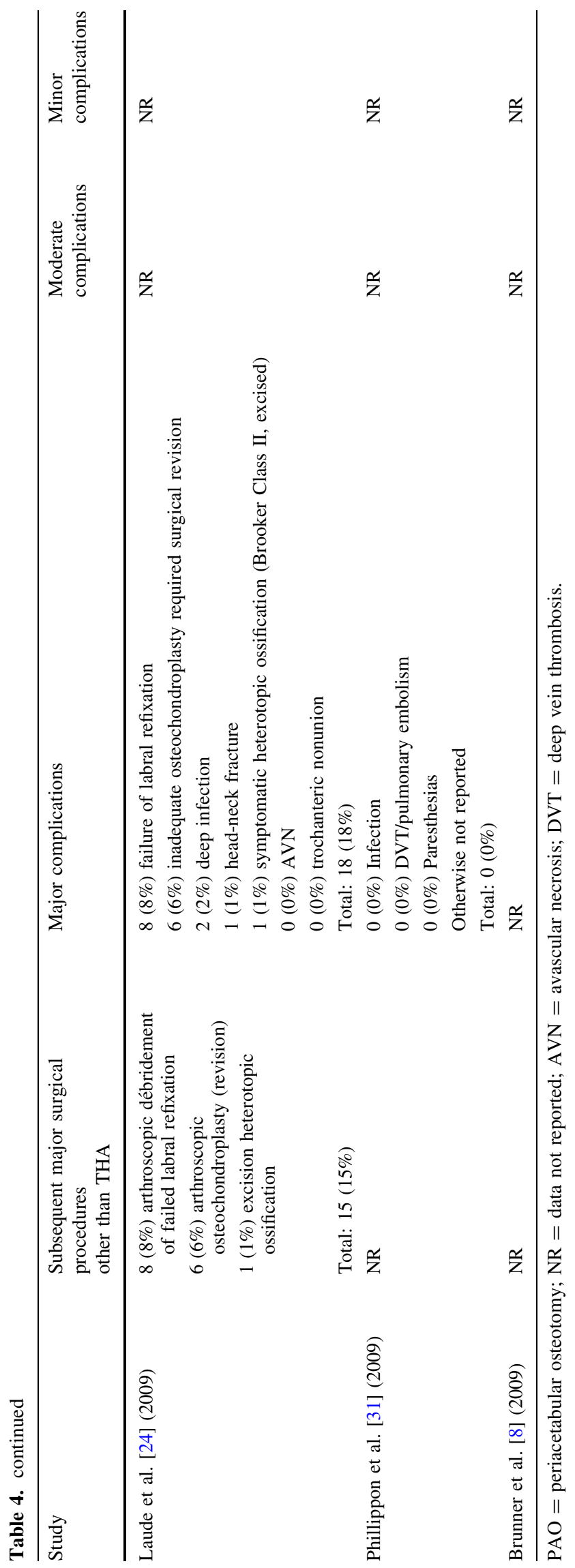

Data were extracted by one reviewer (LSJ) into prearranged summary tables. Potential biases that may have affected the quality of conclusions were identified and discussed among the three authors. Items reviewed included study design, level of evidence, potential bias, aim of the study, inclusion and exclusion criteria, groups in study, loss to followup, surgical techniques, clinical outcome measures, clinically important findings, independent assessment, confidence intervals, and statistics used. Clinical outcome measures varied among studies, as did the method of reporting failures. Clinical results were categorized as good or excellent in three of the eleven studies. All three studies reporting "good or excellent" outcome utilized the Merle D'Aubigné-Postel score and a result was considered to be good or excellent when the total score was 15 to 18 points, fair when it was 12,13 or 14 points, and poor when it was less than 12 points. Clinical failures are summarized using the criteria established in each study when such criteria were established but also reported using the objective end point of conversion to THA in all studies (Table 2). When reported, surgical techniques and procedures were summarized in a consistent manner (Tables 3). Nevertheless, inconsistencies in the reporting of surgical details were common.

Complications were also difficult to collectively evaluate due to reporting inconsistencies. Therefore, we summarized the complications as reported in each study and attempted to grade the complications into major, moderate, and minor categories (Table 4). Major complications included avascular necrosis, femoral head-neck fracture, loss of fixation requiring reoperation, trochanteric nonunion, failure of labral refixation, inadequate osteochondroplasty requiring surgical revision, deep infection, and symptomatic or clinically important limitation of hip motion from heterotopic ossification. Moderate complications consisted of symptomatic hardware (with or without removal). Minor complications included asymptomatic or minimal heterotopic ossification and miscellaneous (urinary tract infection, postoperative fever, etc).

\section{Results}

The current evidence regarding FAI surgery is primarily Level IV (Table 1). Nine of the 11 articles meeting our inclusion criteria were Level IV and two were Level III. No Level I or II studies were identified with our search. Espinosa et al. [14] published a Level III retrospective study comparing the clinical outcome of patients treated for FAI with labral refixation to patients treated with labral resection. Better outcomes were reported in the group of patients who underwent labral refixation. The report by Laude et al. [24] is also a Level III retrospective study, and 
when comparing labral refixation with partial resection, the investigators observed no difference in the nonarthritic hip score. No additional Level III studies were identified. Possible selection bias was identified in two studies [8, 14] due to excessive exclusion of patients. Additionally, the reports by Murphy et al. [29] and Peters and Erickson [30] had cases (five hips total) treated with additional procedures for structural instability in conjunction with the impingement surgery. These cases represent a distinct subgroup of patients whose clinical results may not be representative of FAI surgical cases.

Improvement in hip function was noted in all studies and in three studies clinical outcome scores corresponding to good or excellent results (as defined by a Merle d'AubignéPostel score of 15 to 18 points) were reported in $68 \%$ to $96 \%$ of patients at a minimum followup of 2 years (mean, 3.2 years; range, 2-5.2 years) (Table 2). The Merle d'Aubigné-Postel score was the most commonly used clinical outcome measure (four of 11 studies). The mean improvement in the Merle d'Aubigné-Postel score ranged from 2.4 to 5 points. Other commonly used outcome measures included the WOMAC osteoarthritis index (three studies) and the nonarthritic hip score (three studies), which had mean improvements ranging from 7 to 20.2 points and 14 to 31.3 points, respectively. Factors associated with a good outcome and increased satisfaction included no or mild secondary osteoarthritis (five studies), labral refixation for treatment of labral pathology (three studies), young age (two studies), and limited cartilage damage (one study).

Symptomatic hardware requiring removal was the only moderate complication reported. None of the studies reported minor complications. The reporting of complications was quite variable in these studies and there was no standard complication grading scheme for these procedures.

Conversion to THA was reported in $0 \%$ to $26 \%$ of cases. Radiographic osteoarthritis progression was reported in five studies and noted in $0 \%$ to $33 \%$ of cases. Factors associated with surgical failures and conversion to THA included more advanced preoperative osteoarthritis (four studies), advanced articular cartilage disease (four studies), older age (two studies), and more severe preoperative pain (one study). In general, major complications were uncommonly reported yet occurred in $0 \%$ to $18 \%$ of the procedures (Table 4).

\section{Discussion}

Surgical treatment of symptomatic FAI has become more commonplace over the past several years, yet the published data evaluating surgical treatment are limited. Most studies are relatively small, single-surgeon cohorts. Our purposes were to define the level of evidence regarding hip impingement surgery, determine the impact of surgery on hip pain and function, and to investigate treatment failures and complications.

The limitations in the literature are substantial and primarily result from the limited number of published studies, the heterogeneous study methods and surgical techniques used in the included studies. For example, these studies have substantial variability for documenting disease characteristics, describing details of surgical treatment, measuring clinical outcomes and reporting complications. Some studies do not used contemporary validated outcome measures. Additionally, the surgical techniques utilized in the different studies vary. Open [4, 6, 14, 16, 29, 30, 35], combined arthroscopic and limited open [12, 24], and arthroscopic surgical approaches $[2,8,9,15,19,21-23$, 31-33] are summarized in this review. This introduces limitations in making general conclusions because each surgical technique may have unique issues related to clinical outcomes and complications. The description of disease characteristics (labral and articular cartilage lesions) relative to severity, location, and size is also nonuniform in these studies and introduces restrictions in making prognostic conclusions relative to intraarticular findings. Finally, the documentation and reporting of complications related to surgery is extremely variable. There is no consensus or standard system of documenting complications and, therefore, these data may not provide comprehensive information regarding the potential risks of hip impingement surgery.

Given these limitations we have performed a rigorous review of the literature and summarized the current information regarding the outcomes of hip impingement surgery. These data provide a reference for surgeons performing hip impingement surgery and can be utilized for patient counseling and discussions regarding the expectations of surgical treatment. Specifically, functional scores, risk of treatment failure, and potential complications can be derived from these data. Our review encompassed a variety of surgical techniques for treating hip impingement surgery. Despite these various techniques and heterogeneous patient populations the general findings are relatively consistent and therefore the data are more generalizable when compared to single-surgeon case series and represent an overview of surgical treatment results. The systematic review has enabled us to review a large group (496 cases) of FAI procedures and to identify common observations among the different studies.

All studies documented short-term improvement with decreased pain and improved function in the majority (65 to $96 \%$ ) of patients (Table 2). Many of the studies also propose certain factors are associated with a subjectivelydefined fair or poor functional score and/or surgical failure. 
These poor prognostic factors, although variably reported, include more advanced preoperative osteoarthritis, advanced articular cartilage disease, older age, and more severe preoperative pain. These observations highlight the negative impact of secondary osteoarthritis on the longterm results of surgical intervention. Therefore, joint preservation impingement surgery should be undertaken with caution in the presence of secondary osteoarthritis. The reporting of complications was variable but did suggest impingement procedures are relatively safe, with minimal risk for major perioperative complications (Table 4).

In conclusion, our review of the literature suggests hip impingement surgery is associated with early relief of pain and improved function. The impact of impingement procedures on long-term clinical results and natural history has not been established. The role of nonsurgical management has not been defined. These unresolved issues deserve intense investigation. Future research initiatives in this discipline must focus on an improved set of end points to study this patient population more precisely. Refined, standardized, and validated methods of documenting disease classification, measuring clinical outcomes, and reporting perioperative complications are needed to facilitate more sophisticated clinical investigation. Large patient populations must be evaluated to better answer clinically relevant questions. Given this major need for investigation regarding hip impingement disorders, serious consideration should be given to establishing multicenter clinical research initiatives to build consensus regarding optimal outcome endpoints and to analyze clinical outcomes of large patient cohorts. Most importantly, future clinical trials are needed to determine the relative efficacy of nonsurgical and surgical treatment. Predictors of treatment outcome and the efficacy of various surgical techniques need to be established in well-designed clinical trials.

\section{References}

1. Aronson J. Osteoarthritis of the young adult hip: etiology and treatment. Instr Course Lect. 1986;35:119-128.

2. Bardakos NV, Vasconcelos JC, Villar RN. Early outcome of hip arthroscopy for femoroacetabular impingement: the role of femoral osteoplasty in symptomatic improvement. J Bone Joint Surg Br. 2008;90:1570-1575.

3. Beaule PE. Femoroacetabular impingement: current status of diagnosis and treatment: editorial comment. Clin Orthop Relat Res. 2009;467:603-604.

4. Beaule PE, Le Duff MJ, Zaragoza E. Quality of life following femoral head-neck osteochondroplasty for femoroacetabular impingement. J Bone Joint Surg Am. 2007;89:773-779.

5. Beck M, Kalhor M, Leunig M, Ganz R. Hip morphology influences the pattern of damage to the acetabular cartilage: femoroacetabular impingement as a cause of early osteoarthritis of the hip. J Bone Joint Surg Br. 2005;87:1012-1018.

6. Beck M, Leunig M, Parvizi J, Boutier V, Wyss D, Ganz R. Anterior femoroacetabular impingement: part II. Midterm results of surgical treatment. Clin Orthop Relat Res. 2004;418:67-73.

7. Bedi A, Chen N, Robertson W, Kelly BT. The management of labral tears and femoroacetabular impingement of the hip in the young, active patient. Arthroscopy. 2008;24:1135-1145.

8. Brunner A, Horisberger M, Herzog RF. Sports and recreation activity of patients with femoroacetabular impingement before and after arthroscopic osteoplasty. Am J Sports Med. 2009;37:917-922.

9. Byrd JW, Jones KS. Arthroscopic femoroplasty in the management of cam-type femoroacetabular impingement. Clin Orthop Relat Res. 2009;467:739-746.

10. Clohisy JC, Beaule PE, O’Malley A, Safran MR, Schoenecker P. AOA symposium. Hip disease in the young adult: current concepts of etiology and surgical treatment. J Bone Joint Surg Am. 2008;90:2267-2281.

11. Clohisy JC, Knaus ER, Hunt DM, Lesher JM, Harris-Hayes M, Prather H. Clinical presentation of patients with symptomatic anterior hip impingement. Clin Orthop Relat Res. 2009;467:638644.

12. Clohisy JC, McClure JT. Treatment of anterior femoroacetabular impingement with combined hip arthroscopy and limited anterior decompression. Iowa Orthop J. 2005;25:164-171.

13. Crawford JR, Villar RN. Current concepts in the management of femoroacetabular impingement. J Bone Joint Surg Br. 2005;87: 1459-1462.

14. Espinosa N, Rothenfluh DA, Beck M, Ganz R, Leunig M. Treatment of femoro-acetabular impingement: preliminary results of labral refixation. J Bone Joint Surg Am. 2006;88:925-935.

15. Gaine WJ, Mohammed A. Osteophyte impingement of the popliteus tendon as a cause of lateral knee joint pain. Knee. 2002;9: 249-252.

16. Ganz R, Gill TJ, Gautier E, Ganz K, Krugel N, Berlemann U. Surgical dislocation of the adult hip a technique with full access to the femoral head and acetabulum without the risk of avascular necrosis. J Bone Joint Surg Br. 2001;83:1119-1124.

17. Ganz R, Leunig M, Leunig-Ganz K, Harris WH. The etiology of osteoarthritis of the hip: an integrated mechanical concept. Clin Orthop Relat Res. 2008;466:264-272.

18. Ganz R, Parvizi J, Beck M, Leunig M, Notzli H, Siebenrock KA. Femoroacetabular impingement: a cause for osteoarthritis of the hip. Clin Orthop Relat Res. 2003;417:112-120.

19. Guanche CA, Bare AA. Arthroscopic treatment of femoroacetabular impingement. Arthroscopy. 2006;22:95-106.

20. Hartmann A, Günther KP. Arthroscopically assisted anterior decompression for femoroacetabular impingement: technique and early clinical results. Arch Orthop Trauma Surg. 2009;129:10011009.

21. Ilizaliturri VM, Jr., Nossa-Barrera JM, Acosta-Rodriguez E, Camacho-Galindo J. Arthroscopic treatment of femoroacetabular impingement secondary to paediatric hip disorders. J Bone Joint Surg Br. 2007;89:1025-1030.

22. Ilizaliturri VM, Jr., Orozco-Rodriguez L, Acosta-Rodriguez E, Camacho-Galindo J. Arthroscopic treatment of cam-type femoroacetabular impingement: preliminary report at 2 years minimum follow-up. J Arthroplasty. 2008;23:226-234.

23. Larson CM, Giveans MR. Arthroscopic debridement versus refixation of the acetabular labrum associated with femoroacetabular impingement. Arthroscopy. 2009;25:369-376.

24. Laude F, Sariali E, Nogier A. Femoroacetabular impingement treatment using arthroscopy and anterior approach. Clin Orthop Relat Res. 2009;467:747-752. 
25. Lavigne M, Parvizi J, Beck M, Siebenrock KA, Ganz R, Leunig M. Anterior femoroacetabular impingement: part I. Techniques of joint preserving surgery. Clin Orthop Relat Res. 2004;418: 61-66.

26. Leunig M, Beaule PE, Ganz R. The concept of femoroacetabular impingement: current status and future perspectives. Clin Orthop Relat Res. 2009;467:616-622.

27. Leunig M, Beck M, Dora C, Ganz R. Femoroacetabular impingement: etiology and surgical concept. Oper Tech Orthop. 2005;15:247-255.

28. Leunig M, Casillas MM, Hamlet M, Hersche O, Notzli H, Slongo T, Ganz R. Slipped capital femoral epiphysis: early mechanical damage to the acetabular cartilage by a prominent femoral metaphysis. Acta Orthop Scand. 2000;71:370-375.

29. Murphy S, Tannast M, Kim YJ, Buly R, Millis MB. Debridement of the adult hip for femoroacetabular impingement: indications and preliminary clinical results. Clin Orthop Relat Res. 2004;429:178-181.

30. Peters CL, Erickson JA. Treatment of femoro-acetabular impingement with surgical dislocation and debridement in young adults. J Bone Joint Surg Am. 2006;88:1735-1741.

31. Philippon MJ, Briggs KK, Yen YM, Kuppersmith DA. Outcomes following hip arthroscopy for femoroacetabular impingement with associated chondrolabral dysfunction: minimum two-year follow-up. J Bone Joint Surg Br. 2009;91:16-23.
32. Philippon MJ, Schenker ML. Arthroscopy for the treatment of femoroacetabular impingement in the athlete. Clin Sports Med. 2006;25:299-308, ix.

33. Philippon MJ, Schenker ML. A new method for acetabular rim trimming and labral repair. Clin Sports Med. 2006;25:293-297, ix.

34. Reynolds D, Lucas J, Klaue K. Retroversion of the acetabulum. A cause of hip pain. J Bone Joint SurgBr. 1999;81:281-288.

35. Siebenrock KA, Schoeniger R, Ganz R. Anterior femoro-acetabular impingement due to acetabular retroversion. Treatment with periacetabular osteotomy. J Bone Joint Surg Am. 2003;85:278-286.

36. Siebenrock KA, Wahab KH, Werlen S, Kalhor M, Leunig M, Ganz R. Abnormal extension of the femoral head epiphysis as a cause of cam impingement. Clin Orthop Relat Res. 2004;418:54-60.

37. Snow SW, Keret D, Scarangella S, Bowen JR. Anterior impingement of the femoral head: a late phenomenon of LeggCalve-Perthes' disease. J Pediatr Orthop. 1993;13:286-289.

38. Tannast M, Goricki D, Beck M, Murphy SB, Siebenrock KA. Hip damage occurs at the zone of femoroacetabular impingement. Clin Orthop Relat Res. 2008;466:273-280.

39. Tanzer M, Noiseux N. Osseous abnormalities and early osteoarthritis: the role of hip impingement. Clin Orthop Relat Res. 2004;429:170-177.

40. Wisniewski SJ, Grogg B. Femoroacetabular impingement: an overlooked cause of hip pain. Am J Phys Med Rehabil. 2006;85:546-549. 